\title{
Anastomotic integrity after operations for large-bowel cancer: a multicentre study
}

\author{
L P FIELDING， SARAH STEWART-BROWN， LYNDA BLESOVSKY， GILLIAN KEARNEY
}

\section{Summary and conclusions}

Clinically evident anastomotic dehiscence was studied in 1466 patients who had undergone resection of a largebowel adenocarcinoma. The overall incidence of anastomotic leakage was $13 \%$, but the incidence varied between surgeons (range $0.5 \%$ to over $30 \%$ ). Morbidity and mortality were significantly higher in those patients in whom the anastomosis failed to heal primarily.

If these results are extrapolated to the national level, it should be possible by achieving results closer to those in patients without leakage to reduce overall postoperative mortality after resection of large-bowel cancer by $2 \%$ and to achieve an appreciable reduction in morbidity. ${ }^{4}$ Both factors are clinically important and, taken together, could result in appreciable saving of revenue.

\section{Introduction}

Surgeons recognise that morbidity and mortality are appreciably higher in patients whose enteric anastomosis breaks down than in patients who have an uneventful postoperative recovery. Data from controlled trials and from reports of personal series show a surprising variation of $8-50 \%$ in the incidence of anastomotic leakage. ${ }^{1-10}$ These differences are partly explained by the methods of defining anastomotic dehiscence (the incidence being higher when results of water-soluble contrast radiography are compared. with clinical evidence alone). Nevertheless, apparently similar techniques seem to be associated with different rates of anastomotic breakdown, and therefore other factors probably contribute to the observed results-for example, completeness of bowel preparation, the use of systemic prophylactic antimicrobial agents, the nature of the patient population, and surgical skill.

The data in this report come from the Large-Bowel Cancer

\footnotetext{
Large-Bowel Cancer Project, Academic Surgical Unit, St Mary's Hospital Medical School, London W2 1PG

L P FIELDING, FRCS, assistant director

SARAH STEWART-BROWN, MRCP, research fellow

LYNDA BLESOVSKY, BA, research assistant

GILLIAN KEARNEY, computer programmer
}

Project, in which clinical information on all patients presenting for treatment of tumours of the large bowel is being documented in collaboration with 84 participating surgeons. Part of the study was to determine whether the maintenance of anastomotic integrity is a surgeon-related rather than a patient-related variable. ${ }^{11}$

\section{Patients and methods}

This prospective study started in May 1976, and 84 surgeons in 23 hospitals are current taking part. The records of all patients with a diagnosis of colorectal cancer were collated by specially trained researchers, who travelled to the hospitals concerned to review the case records, operating theatre, and histopathology documents. Information was stored in a computer (Imperial College, London) using a structured data base (INFOL system), and data analysis was carried out using the programme suite Statistical Package for the Social Sciences. ${ }^{12}$

The records of 2430 patients with adenocarcinoma of the large bowel were studied; 2132 of these patients underwent tumour resection, in 1466 of whom an enteric anastomosis was fashioned. The results described are those relating to the treatment of the presenting condition and include all operations required to achieve an end result-either the patient's discharge from hospital or death. Postoperative mortality is defined as death occurring while patients were undergoing treatment in hospital. Longer follow-up information on the patients is not yet available.

The breakdown of anastomotic integrity was accepted on clinical grounds (i) when a frank faecal fistula was present; (ii) when anastomotic breakdown was seen at laparotomy or post mortem in association with peritonitis; (iii) when a patient exhibited clinical features of an anastomotic leak, which was then confirmed by sigmoidoscopy or rectal examination; and (iv) when certain types of intra-abdominal abscess were seen (only 10 cases were included under this definition: two were confirmed at necropsy, three at laparotomy, and five after careful clinical review).

These criteria were adhered to strictly, and thus the incidence of anastomotic leakage may have been underestimated. Statistical analysis was carried out using the $\chi^{2}$ test ${ }^{13}$ except where otherwise stated.

\section{Results}

OVERALL GROUP FIGURES (table I)

A clinically diagnosed anastomotic leak occurred in 191 (13\%) of the 1466 patients studied. The incidence of anastomotic breakdown 
was significantly higher after anterior resection of the rectum compared with intraperitoneal enteric anastomosis $(18.7 \%$ and $10.8 \%$ respectively, $\mathrm{p}<0.001)$. There was little difference in the incidence of anastomotic breakdown when patients treated with perioperative prophylactic systemic antimicrobial agents were compared with those in whom such agents were not used $(11 \%$ and $14 \%$ respectively, $0 \cdot 2>p>0 \cdot 1)$. Similarly, the patients' age, the form of clinical presentation (elective, obstruction, or perforation), the named suture technique (one-layer or two-layer method), and the grade of surgeon carrying out the anastomosis (fully trained or trainee) were not associated with any overall differences in anastomotic leakage.

TABLE I-Overall incidence of anastomotic leakage according to recorded variables

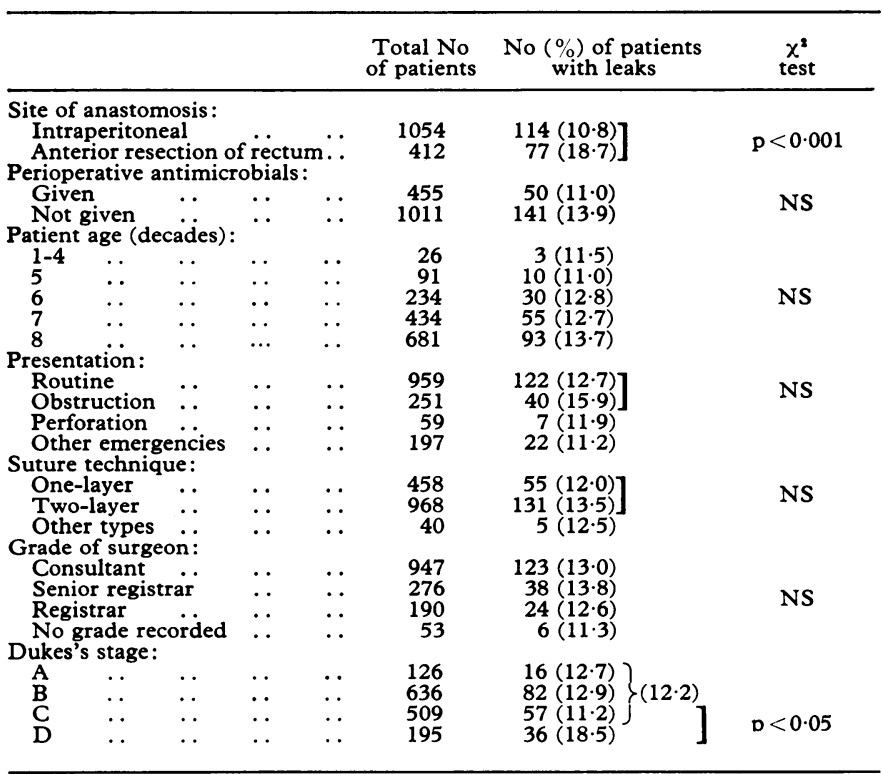

NS: No statistical difference at $5 \%$ level.

Furthermore, the incidence of leakage was similar whatever the degree of local tumour spread in patients who had a "curative" resection (Dukes's stages A, B, and C), but those patients who had had a "palliative" resection had a significantly higher incidence of leakage (after curative resection $12.2 \%$ and after palliative resection (grade D) $18.5 \%(\mathrm{p}<0.05)$ ).

Of the 251 patients who presented with obstruction, 67 underwent a staged tumour resection; in nine of these $(13.4 \%)$ the anastomosis leaked. In the remainder (184 patients) the tumour was excised at the first operation (primary tumour resection). Of these patients, $127 \mathrm{did}$ not have a "covering" transverse colostomy (18 $(14 \%)$ with anastomotic leakage), 28 had such a stoma (seven $(25 \%)$ with leakage), and in 29 the reconstruction was delayed to a second operation (six $(21 \%)$ with leakage). Transverse colostomy did not seem to confer any overall advantage to these patients in terms of mortality (table II), and the lowest mortality occurred in the group in whom the anastomosis was delayed.

Ninety-one $(7 \cdot 1 \%)$ of the 1275 patients without anastomotic leakage and $42(22.0 \%)$ of the 191 with leakage died in hospital $(\mathrm{p}<0.001)$. Thus 1184 patients without leakage and 149 with leakage

TABLE II-Mortality in patients, undergoing primary tumour resection and anastomosis for obstruction

\begin{tabular}{|c|c|c|c|c|c|c|}
\hline & \multicolumn{2}{|c|}{ All patients } & \multicolumn{2}{|c|}{$\begin{array}{c}\begin{array}{c}\text { Patients without } \\
\text { leakage }\end{array} \\
\end{array}$} & \multicolumn{2}{|c|}{$\begin{array}{c}\text { Patients with } \\
\text { leakage }\end{array}$} \\
\hline & Total & $\begin{array}{l}\text { No }(\%) \\
\text { dying }\end{array}$ & Total & $\begin{array}{l}\text { No }(\%) \\
\text { dying }\end{array}$ & Total & $\begin{array}{l}\text { No (\%) } \\
\text { dying }\end{array}$ \\
\hline $\begin{array}{l}\text { Anastomosis without stoma } \\
\text { Anastomosis with transverse }\end{array}$ & 127 & $19(15)$ & 109 & $15(14)$ & $18(14)$ & $4(22)$ \\
\hline $\begin{array}{cc}\text { colostomy } \\
\text { Delayed anastomosis }\end{array}$ & $\begin{array}{l}28 \\
29 *\end{array}$ & $\begin{array}{l}6(21) \\
1 \text { (3) }\end{array}$ & $\begin{array}{l}21 \\
23\end{array}$ & $\begin{array}{l}4(19) \\
0\end{array}$ & $\begin{array}{l}7(25) \\
6(21)\end{array}$ & $\begin{array}{l}2 \\
1\end{array}$ \\
\hline
\end{tabular}

* Comparison of mortality after delayed anastomosis and after anastomosis with transverse colostomy: $0 \cdot 1>\mathrm{p}>0.05$. left hospital alive. The median duration of hospital stay for these patients was 25.4 days for those without leakage and $45 \cdot 7$ days for those with leakage $(p<0.001$, Student's $t$ test for unpaired data). Thus anastomotic breakdown is associated with a twofold increase in the duration of hospital stay and a threefold increase in hospital mortality.

\section{COMPARISON BETWEEN SURGEONS}

The frequency distribution of anastomotic dehiscence for each senior surgeon with clinical responsibility for patient care ranged from $0-5 \%$ to over $30 \%$ (table III). Surgeons with relatively few anastomoses in their series (fewer than 20 patients) were excluded from this analysis to remove any possible distortion caused by the small numbers, despite the observation that the overall incidence of dehiscence for each surgeon appeared to be independent of the number of anastomoses fashioned (under 10 patients $12.3 \% ; 10-19$ patients $13.7 \% ; 20$ or more patients $12.8 \%$ )

TABLE III-Frequency distribution of anastomotic dehiscence related to senior (consultant) surgeon with primary clinical responsibility for patient carethat is, irrespective of grade of operating surgeon-excluding surgeons with fewer than 20 patients in the series

\begin{tabular}{lccccccc}
\hline$\%$ of anastomoses leaking: & $0-5$ & $6-10$ & $11-15$ & $16-20$ & $21-25$ & $26-30$ & $31-35$ \\
No of surgeons $(n=28):$ & 5 & 9 & 3 & 3 & 4 & 4
\end{tabular}

Mean rate of leakage $=12 \cdot 8 \%$

This disparity might conceivably be accounted for by significant differences in the incidences of the two factors that influence the overall results-namely, anterior resection of the rectum and palliative tumour resection. Further analysis, however, shows that the relative frequency of anterior resection of the rectum does not explain the differences observed between surgeons, because similar incidences of anastomotic leakage occur for those with relatively few or large numbers of patients undergoing restorative resection of the rectum (figure). Furthermore, the overall incidence of disseminated

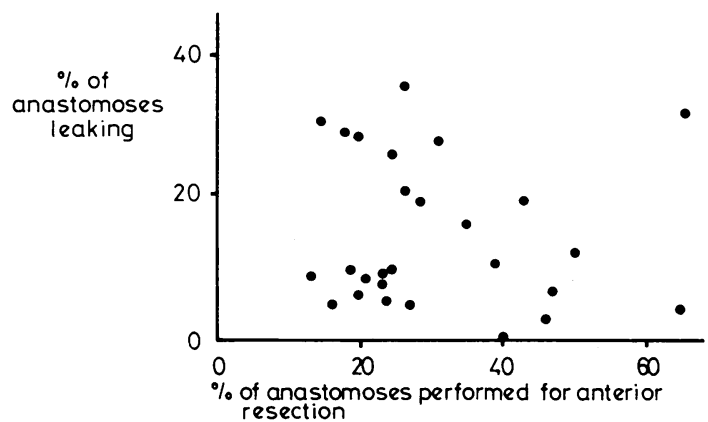

Percentage of anastomoses leaking plotted against percentage of anastomoses performed for anterior resection for each senior (consultant) surgeon with primary clinical responsibility for patient care. (Analysis of variance applied to the regression shows no statistical relation: $r^{2}=0 \cdot 01$.)

disease in patients with an anastomosis (palliative resections) was only $16.6 \%$ and the incidence for each surgeon was sufficiently simila that the wide range in the incidence of anastomotic dehiscence found between surgeons cannot be explained by an uneven distribution of patients undergoing palliative resections. Finally, it might be suggested that these differences may be systematically related to the differen types of hospitals taking part in the study. Of the 23 hospitals, 15 were district general hospitals and eight teaching hospitals (including one specialist hospital); no differences were found in the incidences of anastomotic leakage for surgeons when grouped according to this broad classification of hospital type (range $0-5 \%$ to $25-30 \%$ in both cases; mean values $13.1 \%$ in district general hospitals and $12.9 \%$ in teaching hospitals-table IV). 
TABLE IV-Frequency distribution of anastomotic dehiscence grouped according to type of hospital

\begin{tabular}{|c|c|c|c|c|c|c|}
\hline \multirow{2}{*}{ Type of hospital } & \multicolumn{6}{|c|}{$\%$ of anastomoses leaking: } \\
\hline & $0-5$ & $6-10$ & $11-15$ & $16-20$ & $21-25$ & $26-30$ \\
\hline $\begin{array}{l}\text { Teaching }(n=8)^{*} \ldots \\
\text { District general }(n=15)+\ldots\end{array}$ & $\begin{array}{l}1 \\
1\end{array}$ & $\begin{array}{l}2 \\
4\end{array}$ & $\begin{array}{l}2 \\
6\end{array}$ & $\frac{1}{2}$ & $\begin{array}{l}1 \\
1\end{array}$ & $\begin{array}{l}1 \\
1\end{array}$ \\
\hline
\end{tabular}

*Number of patients with anastomoses was 513 ; mean incidence of leakage was $12.9 \%$ * Number of patients with anastomoses was 513 ; mean incidence of leakage was $12.9 \%$.
+ Number of patients with anastomoses was 953 ; mean incidence of leakage was $13.1 \%$

\section{Discussion}

These data confirm the results of other studies ${ }^{2} 45$ in which the incidence of anastomotic leakage after anterior resection of the rectum was significantly higher than that after intraperitoneal anastomosis. There are, however, some exceptions to this generalisation. ${ }^{6} 9$ Perioperative systemic antimicrobial agents may be of some benefit in reducing anastomotic leakage, but our data show only a marginal difference, which failed to reach significance at the $5 \%$ level. The effect of this variable taken in isolation, however, may have been obscured by other factors of greater importance, and more specifically directed prospective studies are required to answer this question ( $R$ Grace, personal communication). ${ }^{14}$ We were surprised to find a similar range of results emanating from both district general and teaching hospitals, but perhaps our sample was too small for us to draw any firm conclusions about this issue except that the true overall differences between hospital types are unlikely to be large.

Our results highlight the clinical seriousness of anastomotic dehiscence in that the duration of hospital stay was doubled and there was a threefold difference in postoperative mortality when this complication occurred. Clearly, the reason for the occurrence of anastomotic breakdown is multifactorial; both clinical and laboratory studies have emphasised different aspects of the problem, including collagen lysis and synthesis, anastomotic bursting pressure, and local blood supply..$^{15-20}$ Although the prerequisites for a successful anastomosis are well known, clearly they are either not being used or are being deployed unsuccessfully in an appreciable number of patients.

The data in the current study show that the surgeon who has clinical responsibility for the care of the patient is probably the most important single factor influencing anastomotic integrity. Such a statement about surgical technique may be thought controversial, bu there is a sixfold range of results (about $5-30 \%$ ) that cannot be accounted for by any obvious differences in patient population. Furthermore, evidence shows that when particular attention is given to a potentially difficult or hazardous anastomosis the results may be better than for the routine case. ${ }^{21} 22$

What can be done about this problem ? Perhaps the anastomosis should be tested with water-soluble contrast radiography between the eighth and tenth postoperative days to provide a useful objective criterion that might help assess surgical performance and hence lead to improved results. If this view were adopted it would be essential that this investigation be carried out without risk to the anastomosis by using small volumes of contrast medium and omitting air insufflation during the investigation. Perhaps more widespread use of the end-to-end anastomosis stapling guns ${ }^{23}$ would improve results. Although these instruments might help, they are applicable to only the rectosigmoid area and poor results have occurred in all parts of the colon in this and other studies. ${ }^{3}$ Furthermore, long-term results concerning the formation of strictures of the anastomosis and tumour recurrence ${ }^{24}$ are unknown when such stapling instruments are used.

Our next objective is to debate, within our group, the possible reasons for these surgeon-related differences in an attempt to define and describe the methods that are associated with the "best" outcome-for example, the exact procedure for bowel mobilisation to preserve blood supply, suture materials and technique, use of drains and "covering" stomas, the place of stapling machines and postoperative water-soluble contrast examinations, and, no doubt, other issues. We are encouraged to pursue this approach because the incidence of anastomotic leakage within our group of surgeons seemed to begin to diminish after preliminary discussion of these findings, the incidence between June 1976. and October 1977 being 134/943 (14.2\%), and from November 1977, 57/523 (10.9\%)-0.1>p >0.05.

Assuming that our overall results may be brought nearer to those obtained in patients without anastomotic dehiscence, we might expect to see an overall improvement in outcome for patients having resectional operations of about $2 \%$ for mortality and a $9 \%$ reduction in the duration of hospital stay for those patients leaving hospital alive. We estimate that the population served by our study is about $3 \%$ of that in Britain. Extrapolating from these figures to the national level, and if the rates of anastomotic dehiscence could be reduced to $5 \%$, then this might prevent the postoperative death of about 450 patients and save some $£ 4 \mathrm{~m}$ a year. Furthermore, in the wider context of surgery for large-bowel cancer it should be possible to reduce the overall duration of hospital stay and mortality of patients to about 20 days and $5 \%$ respectively. The commensurate increase in preservation of life and financial resources would be about double the figures just mentioned.

We gratefully acknowledge the co-operation of the surgeons who took part in the study, and their associated colleagues:

D W Blair, A I Davidson, J Engesett, P R Jones, J Kyle, N G Matheson, S S Miller, G Smith, Aberdeen Royal Infirmary, Aberdeen; N Baker, O D Morris, Ashford General Hospital, Ashford, Middlesex; A A Gunn, D A D Macleod, Bangour General Hospital, Broxbourne, West Lothian; W A Anderson, K Callum, P Goodall, G Harrison, S G Hollander, D R Thomas, Derby Royal Infirmary, Derby; J W P Bradley, T J C Cooke, J V Piper, J E L Sales, C G Scorer, Hillingdon Hospital, Hillingdon, Middlesex; J Chamberlain, A H Petty, C W Venables, R G Wilson, Newcastle General Hospital, Newcastle upon Tyne; H B Devlin, A Peel, North Tees General Hospital, Stockton-on-Tees; A G Cox, A Elton, A E Kark, J Lewis, D Pinto, Northwick Park Hospital, Harrow, Middlesex; A Davidson, Perth Royal Infirmary, Perth; G L Bohn, D Goodwin, C S Kirkham, C Latto, M Ross, G Rothnie, Royal Berkshire Hospital and Battle Hospital, Reading, Berkshire; R H Grace, Royal Hospital, Wolverhampton; A Chant, Professor Sir James Fraser, S Karran, J Webster, Royal Southants Hospital, Southampton; P H Dickinson, L B Fleming, F D Hindmarsh, I D A Johnston, I F McNeil, R Taylor, Royal Victoria Infirmary, Newcastle upon Tyne; A S Chilvers, J M Edwards, B P Flannery, A G Nash, B W Wells, St Helier Hospital, Carshalton, Surrey; P R Hawley, H E Lockhart-Mummery, C V Mann, Sir Alan Parks, J Thomson, I Todd, St Mark's Hospital, London EC1; Professor H A F Dudley, H H Eastcott, L P Fielding, G Glazer, J R Kenyon, St Mary's Hospitals, London W2 and W9; A V Pollock, Scarborough Hospital, Scarborough, Yorkshire; S Desai, M Horwich, C Maddox, A S Oscier, Scunthorpe General Hospital, Scunthorpe, Lincolnshire; J Jenkins, F P McGinn, T Rowntree, C J Smart, Southampton General Hospital, Southampton; P Cassell, R Ramsay, E J Williams, Wexham Park Hospital, Slough, Buckinghamshire; D Cairns, J L Grogono, B Higgs, P H Lord, Wycombe and Amersham General Hospitals, High Wycombe and Amersham, Buckinghamshire.

We thank Professor H A F Dudley for help in preparing the manuscript.

We gratefully acknowledge financial support from Downs Surgical Ltd; the Jessie Willment Bequest; the locally organised research scheme, North-west Thames Regional Health Authority; and the Cancer Research Campaign.

Requests for reprints should be sent to LPF.

\section{References}

${ }^{1}$ Clark CG, Elmasri S, Harris J, Whyllie JH, Dow J. Polyglycolic-acid suture and catgut in colonic anastomoses. A controlled clinical trial. Lancet 1972;ii:1006-7.

2 Collins JP, Butterfield D. The results of colonic anastomoses at the Royal Melbourne Hospital. Aust NZ F Surg 1978;48:409-11.

${ }^{3}$ Debas HT, Thompson FB. A critical review of colectomy with anastomosis. Surg Gynecol Obstet 1972;135:747-52.

4 Everett WG. A comparison of one-layer and two-layer technique for colorectal anastomoses. Br f Surg 1975;62:135-40. 
5 Goligher JC, Lee PWR, McMahon MJ. A controlled comparison of oneand two-layer techniques for suture of high and low colorectal anastomoses. Br f Surg 1977;64:609-12.

${ }^{6}$ Goligher JC, Lee PWR, Lintott DJ. Experience with the Russian Model 24G suture gun for anastomoses of the rectum. Surg Gynecol Obstet $1979 ; 148: 517-24$.

7 Jonell G, Edelmann G. Single-layer anastomosis of the colon. Am $\mathcal{F}$ Surg $1978 ; 135: 630-2$.

${ }^{8}$ Letwen ER. Evaluation of polyglycolic acid sutures in colon anastomoses. Can f Surg 1975;18:31-2.

9 Matheson NA, Irving AD. Single-layer anastomoses after recto-sigmoidal resection. Br F Surg 1975;62:239-42.

10 Sharma CM. Single-layer anastomoses in colon surgery. $\mathcal{f} R$ Coll Surg Edinb $1977 ; 22: 214-7$

11 Fielding LP, Stewart-Brown S, Dudley HAF. Surgeon-related variables and the clinical trial. Lancet 1978 ;ii:778-81.

${ }^{12} \mathrm{Nie} \mathrm{NH}$, Bent DH, Hull CH. SPSS: statistical package for the social sciences. New York: McGraw-Hill, 1970.

13 Siegal S. Non-parametric statistics for the behavioural sciences. International student ed. New York: McGraw-Hill Kogakualion, 1956:104.

14 Keighley MRB, Alexander-Williams J, Arabi Y, Youngs D, Burdon DW. Comparison between systemic and oral antimicrobial prophylaxis in colorectal surgery. Lancet 1979 ;i :894-7.

15 Hunt TK, Hawley PR. Surgical judgment and colonic anastomoses. Dis Colon Rectum 1969;12:167.
${ }^{16}$ Hawley PR. Causes and prevention of colonic anastomotic breakdown. Dis Colon Rectum 1973;16:272.

17 Shrock TR, Deveney CW, Dunphy JE. Factors contributing to leakage of colonic anastomoses. Ann Surg 1973;177:513.

18 Cronin K, Jackson DS, Dunphy JE. Changing bursting strength and collagen content of the healing colon. Surg Gynecol Obstet 1968;126:747.

19 Ehrlich HP, Hunt TK Effects of cortisone and vitamin A on wound healing. Ann Surg 1968;167:324.

20 Wile L, McAlister W, Stein T, et al. Studies on the healing of anastomose of small and large intestine. Surg Gynecol Obstet 1975;141:190.

21 Smith AN, Duncan W, Freedman L. Medical Research Council trial. Preoperative radiotherapy in operable rectal cancer. Gut (in press)

22 Thow GB. Emergency left colon resection with primary anastomosis. Dis Colon Rectum 1980;23:17-24.

${ }^{23}$ Heald RJ. Towards fewer colostomies-the impact of circular stapling devices on the surgery of rectal cancer in a district hospital. $\mathrm{Br} \mathcal{F}$ Surg $1980 ; 67: 198-200$

${ }^{24}$ Keller JW, Kelley HG, Kinsey DL. Efficiency of iodized suture in prevention of suture transferral of malignant tumours. Cancer 1966 19:549.

${ }^{25}$ Goligher JC. Recent trends in the practice of sphincter saving excision of the rectum. Ann R Coll Surg Engl 1979;61:169-73.

(Accepted 24 fune 1980)

\title{
Twenty-four-hour metabolic profiles in diabetic children receiving insulin injections once or twice daily
}

\author{
G A WERTHER, P A JENKINS, R C TURNER, J D BAUM
}

\section{Summary and conclusions}

Twenty-four-hour meciabolic profiles were performed twice in each of 15 diabetic children, once when they were receiving single daily injections of insulin (Monotard plus Actrapid) and once on a twice-daily regimen (Semitard plus Actrapid). Before the study control was optimised at home on each regimen. There were no differences in overall 24-hour diabetic control on the two regimens as measured by mean blood glucose concentration, area under the blood glucose curve, $M$ value, and 24-hour urinary glucose excretion. Hyperglycaemia after breakfast occurred on both regimens. Significant differences were noted before breakfast, when blood glucose and ketone concentrations were lower and plasma free insulin higher on the single-injection regimen, and after supper and during the night, when blood glucose values were lower on the two-injection regimen and associated with a rise in plasma free insulin after the evening injection. Once-daily injections provided insufficient circulating insulin after the evening meal, while twicedaily injections did not last through the night. Plasma $C$ peptide, indicating residual endogenous insulin secretion, was just detectable in two children but easily detectable in four children, whose 24-hour diabetic control was significantly better than that in the remaining 11 children.

Department of Paediatrics, University of Oxford, John Radcliffe Hospital, Oxford OX3 9DU

G A WERTHER, MB, FRACP, senior clinical tutor (present address: department of paediatrics, Queen Victoria Medical Centre, Melbourne, Australia)

P A JENKINS, FIMLS, senior medical laboratory scientific officer

J D BAUM, MD, FRCP, clinical reader

Nuffield Department of Clinical Medicine, Radcliffe Infirmary, Oxford

R C TURNER, MD, FRCP, clinical reader
Conclusions about the superiority of one insulin regimen over another must be based on specific differences in diabetic control. Both regimens studied achieved adequate control, and though neither provided physiological control specific modifications to the regimens could help to produce more normal profiles.

\section{Introduction}

There has been much debate whether diabetic patients, both children and adults, should be given insulin once a day or more often. Arguments have been based on several findings and assumptions, including the clinical observation that patients poorly controlled or unstable on a single-injection regimen improve when switched to twice-daily injections. ${ }^{1}$ Other retrospective studies relating long-term complications to poor diabetic control have suggested that patients given multiple daily injections have fewer complications than those on oncedaily injections. ${ }^{2}$ A prospective study in adults showed reduced progress of retinopathy on multiple injections compared with single-injection treatment. ${ }^{34}$ Furthermore, on physiological principles, the normal pattern of circulating insulin can be more closely mimicked by more than one injection of insulin a day. ${ }^{5}$ The findings in adults may not necessarily apply to children, however, because of the greater lability of diabetic control related to variations in growth, exercise, and emotion and to puberty. It has also been suggested that endogenous insulin production may play a greater part in diabetic control in children than in adults. ${ }^{6}$

Most studies comparing different insulin regimens have been limited by imprecise means of assessing diabetic control, such as random urine or blood testing. They have also failed to treat each regimen similarly in the effort devoted to achieving optimal control. Also, few studies have compared diabetic control on highly purified insulin regimens in children or adults. "Monocomponent" and "rarely immunogenic" insulins may have different durations of action from equivalent unpurified 